\title{
An Analysis of the Reasonableness of the Internal Recourse Rights of the Guarantor in Hybrid Joint Security
}

\author{
Xinyu Wu \\ College of Philosophy, Law \& Political Science, Shanghai Normal University, Guilin Road100, Xuhui District, Shanghai, China
}

\begin{abstract}
Security plays an important role in Civil Code. In practice, creditors seek the superposition of multiple guarantees to protect their interests, which may give rise to hybrid joint security. Article 392 of the Civil Code of the People's Republic of China establishes three subordinate agreed priorities for the realization of security rights by creditors, the priority of self-secured property rights, and the creditor's own choice, i.e., it follows the style of the Property Law. However, the Civil Code does not explicitly provide for the issue of the guarantor's internal recourse rights in a hybrid joint security. The article argues that the existing legal system should be adjusted and modified accordingly to realize the guarantor's internal recourse rights in a hybrid joint guarantee.
\end{abstract}

Keywords: Hybrid joint security, Security right, Internal recourse rights, Collateral, Surety.

\section{Introduction}

As the commodity economy continues to develop, creditors are always looking for more security over the same claim in order to ensure that market transactions are fully conducted and to maximize their own protection. Among such joint security, they are defined as "hybrid joint security" due to the different nature of security. However, after the guarantor assumes the responsibility of security, except for the recourse from the debtor, there is no perfect provision in our law for the recourse and remedy relationship between the property security (collateral) and the personal security (surety). This article intends to analyze the rationality of the guarantor's internal recourse right in the hybrid joint security and further explore the scheme of the guarantor's internal recourse rights.

\section{Overview of Hybrid Joint Security Internal Recourse Rights}

\subsection{The Definition of Hybrid Joint Security Internal Recourse Rights}

There is a broad and narrow definition of hybrid joint security recourse rights. In a broad sense, hybrid joint security recourse rights refer to the recourse rights arising from the rights of guarantors in respect of the same claim that are secured by two different types of security. In the narrow sense, the recourse right in hybrid joint security only means the legal recourse rights against other guarantors after assuming the security liability in the case of both the personal security and the property security for the same claim. That is, the right of recourse between guarantors under the coexistence of the personal security and the property security for the same claim. The Civil Code has made clear provisions for the single form of joint security (that is claim with only in personal security and the property security), while the Civil Code has unclear and imperfect provisions on whether and how to exercise the rights of internal recourse right between guarantors when there is both in personal security and the property security for the same claim, resulting in a large number of cases with different judgments in the judicial process. Therefore, the internal recourse rights in hybrid joint security studied in this paper only refers to the narrow sense, i.e. the internal recourse rights between the guarantors in the case of the coexistence of personal and property guarantees.

\subsection{History}

China's legislation on the internal recourse rights of the guarantor in hybrid joint security is ambiguous at the legislative, judicial and academic levels, and there is great room for debate. And different attitudes are held with regard to whether guarantors in a security can recover from each other. In recent years, the trend has been to respect more the principles of egalitarianism and autonomy. The relevant legislative developments are as follows.

(1) Article 28 of the Security Law promulgated and implemented in 1995. This was the first time that the existence of hybrid joint security was explicitly admitted by law. This article was called "absolute priority of property security", when property security coexist, the creditor must first realize the claim on the property security, and the guarantor should only bear the debt other than the property security, which can be defined to be supplementary liability, and there is no mutual recourse between guarantors at all.

(2) Article 38 of the Interpretation on Several Issues Concerning the Application of the Security Law issued by the Supreme People's Court in 2000: This article further explained the relevant provisions of 1995, which mainly conveys the tendency of equalism between the property security and personal security. Moreover, it was the first time to clarify that in the hybrid joint security, the guarantor can recover from other guarantors after taking responsibility.

(3) The "Property Law" enacted in 2007: The Property Law only specified that the autonomy of the parties shall be fully respected.

(4) In 2019, the Ninth Civil Code denied the recourse rights of the guarantors.

(5) Article 392 of the Civil Code to be enacted in 2020: This 
article did not follow the conference spirit of the Ninth Civil Minute and copies the relevant provisions of the Property Law. Article 13 of the Explanation on the Application of the Civil Law Relating to the Security System is concerned with the agreed recourse rights between guarantors, but does not provide for a specific recourse regulation, and is silent on the statutory recourse rights, making the relevant provisions unclear again.

China's legislation on the recourse rights in a hybrid joint security has gone through a "blank-positive-vague-negativevague-negative-vague", which has led to the issue of whether the hybrid joint guarantors enjoy the recourse right among themselves becoming a key and difficult issue in judicial trials today.

\section{The Combing of Hybrid Joint Security Academic and Practice Controversy}

\subsection{Academic Controversy}

Regarding the guarantor's right of internal recourse, the academic circles are divided, and there are mainly two views: "positive" and "negative". The scholars who agree with the "positive theory" think that each guarantor should enjoy the internal recourse rights in the hybrid joint security, mainly for the following reasons: firstly, the principle of equity should be the fundamental basis. For example, Professor Wang Liming thinks that (the recourse rights) system is designed to realize the fair value pursued by the law. If the recourse rights are denied, there will be a big discrepancy with people's simple legal feelings and fair concepts. It is natural for a guarantor to be liable and it is the same whether he is owed to the creditor or to another guarantor, and it will not give rise to injustice. Second, from a purposive point of view, the security rights are created to focus on protecting the interests of creditors, and affirming the recourse rights does not have a direct adverse effect on creditors, but also serves the purpose of spreading the risk for the guarantors together. Some scholars also believe that when some guarantors assume the responsibility of security, other guarantors are exempted from the responsibility, which belongs to the accidental acquisition of benefits, and even will constitute unjust enrichment. Finally, some scholars argue that the guarantor's internal recourse rights should be in accordance with the principle of efficiency first, which is more in line with the common interests of the guarantors as a whole and further saves transaction costs.

Scholars who hold the "negative view" argue that it is inappropriate to recognize the guarantor's internal recourse rights in a hybrid joint security. The main reasons include: first, the lack of theoretical basis. As mentioned above, China's current legislation does not recognize the right of intra-guarantor recourse, so in the absence of either a legal provision or an agreement between the parties, the guarantors cannot claim recourse in a joint and several relationship. Second, the lack of legal basis for the guarantor's internal recourse rights violates autonomy. Scholars believe that the guarantor does not have the intention to provide security with other guarantors, so it should be considered that it is voluntary to secure the ultimate realization of the claim with its guarantee, and should not set joint and several guarantee liability, otherwise it violates the principle of autonomy.
Professor Liu Kaixiang believes that private law autonomy and meaning autonomy, as the soul and ultimate concept of civil law, are more necessary to be placed in the first place at any time and when setting any legal rules (Liu Kaixiang, 2021). Third, the prohibition of internal recourse of guarantors is more in line with the risk expectation of the parties, and it is a violation of the principle of equity if the law imposes interference.

\subsection{Practical Controversy}

When the law does not explicitly prohibit the person who assumes responsibility for the security from recovering from other guarantors, many courts continue to find the internal recourse reasonable. Searching the case law of internal recourse of guarantor in hybrid joint security on the Judicial Documents Website, we can find that among many disputes, the most numerous contract disputes involving internal recourse of guarantor in hybrid joint security are financial lending contract disputes; in the process of adjudication, the courts take a majority of positive attitude, among which the cases in 2020 have the highest support rate, that is, the practice supports the internal recourse of guarantor in hybrid joint security. The guarantors do have the internal recourse rights occupies the mainstream position.

The civil judgment of Hubei High Court (2014) No.00078 and the civil judgment of Jiangxi Shanggao County Court (2021) No.109 of Gan0923 Civil gave different judgments on the internal recourse rights of the property security and personal security between the hybrid joint security. The author believes that the courts generally apply value judgments in approving the rights of internal recourse, and usually also invoke the principles of good faith and fairness. If there is no agreement between the guarantors, the balance of their rights and obligations should be achieved by equitable principles. If one guarantor assumes the liability and the remaining guarantor's liability is extinguished, it would be inequitable and equitable principles should be applied to achieve unity among the guarantors.

The main reason why there is still a big debate in society about the exercise of the internal recourse rights in a hybrid security today is that the law is not clear about the internal recourse rights in a hybrid security. In general, as long as the legislature is not clear about the guarantor's internal recourse rights, judges will be in a difficult position in the specific judicial practice, and there will be a lot of examples of different judgments in the same type of cases in judicial practice, which is not conducive to maintaining the authority of the law.

\section{An Analysis of the Reasonableness of the Internal Recourse Rights of the Guarantor and the Specific Scheme of Recourse}

\subsection{Reasonableness of the Guarantor's Internal Recourse Rights}

The author agrees that the guarantor has the rights to internal recourse in the hybrid joint security. First of all, the Civil Code provides for two types of security: property security and 
personal security, which are not superior or inferior and should be treated equally. According to Article 392 of the Civil Code, both property security and personal security are essentially the guarantee of the creditor's claim by the guarantor's liable property, and there is no substantial difference between them (Gu Xiewei, 2020) Therefore, the author believes that except for the Civil Code, which clearly stipulates that the debtor's self-bond should be realized first, other joint security, third-party property security, and personal security should naturally rank in the same value order, i.e., if it is agreed that the guarantor has the internal recourse right, all the above guarantors have the same internal recourse right. Vice versa.

Secondly, using the method of purposive interpretation, the primary purpose of the guarantee system is to ensure that the creditor can realize his creditor's rights, and the second purpose is to protect the interests of the guarantor and the debtor. As mentioned above, the creation of a recourse right does not adversely affect the creditor, so this paper focuses on how to maximize the interests of the guarantor and the debtor. If there are other guarantees on the debt, the guarantors will realize that they are not the only ones providing guarantees for the debtor, but the rest of the guarantors are also spreading the risk for them, which will facilitate the establishment and performance of the guarantees. On this basis, the existence of recourse between guarantors also helps the debtor to create more guarantees and further protects the rights of creditors in line with the needs of commodity transactions. In addition, if the internal recourse rights in hybrid joint security are denied, because creditors have the right to choose freely, some guarantors may collude with creditors privately and maliciously in order to make themselves bear less risk, and use "bribery" or other forms to make themselves free from debt, which is a foreseeable and unavoidable risk. If the internal recourse rights are recognized, it can effectively prevent malicious collusion and the phenomenon of malicious collusion can be effectively eliminated, which makes the security system more harmonious and helps reflect the fairness of society.

Furthermore, many scholars who hold the negative view believe that joint and several liability is a very strict liability in civil liability. How can guarantors bear the strictest joint and several liability without prior mutual intention? The absence of mutual intent is limited to the absence of mutual intent between the guarantors, but the guarantors are all committed to the same debt, the ultimate purpose of this act are the same, the author seems to each guarantor and the creditor did establish a link, can be said to be a competing relationship or a joint and several relationship. If one guarantor is liable, the original potential liability of the remaining guarantors will be lost or diminished accordingly. Therefore, the guarantors cannot be considered jointly and severally liable from the appearance doctrine alone, as the rights and obligations of the guarantors are in fact intertwined, so why should the creditor simply choose the guarantor to assume the liability? It is true that the guarantor is willing to bear the risk, but there are other debtors who can be liable with him, which is unfair to the selected guarantor. There are also scholars who think that the establishment of the recourse right is against the value of efficiency, for this view I think it will indeed affect the efficiency to a certain extent, but one is the original creditor to realize the guarantee, the guarantor can recover from the debtor, If the "positive" is held, the only effect is that more people can be recovered. The second is that the social cost of the above-mentioned bad faith collusion between the creditor and the guarantor or the guarantor's speculative behavior such as reducing assets to reduce the proportion of their own performance of the debt will be greater than the social cost of internal recourse among guarantors.

Finally, the issue is examined in the context of comparative law. Article 769 of the German Civil Code provides that joint guarantors are considered to bear the joint responsibility even if there is no joint security among them. Article 2029 of the French Civil Code states that "the guarantor of a discharged debt acquires all his rights against the debtor in subrogation to the creditor." The Japanese Civil Code also supports the position that the guarantor in the creation of a hybrid joint guarantee has the rights to internal recourse, and Article 500 of the Japanese Civil Code provides that a person who has a legitimate interest in the satisfaction shall be ex officio subrogated to the creditor by reason of his satisfaction. $(\mathrm{Qu}$ Tao, 2006) The common ground of the laws of the above three countries is that the guarantors are ultimately claimable against each other, rather than bearing all the liability of the guarantor only in different ways. German law is that the guarantor acquires the same status as a creditor after the guarantor has paid off the debt; French law is that the guarantor, based on subrogation, can exercise the rights of the creditor and thus recover from the other co-guarantors; Japanese law assumes liability for the guarantee on a share basis and the guarantor generally does not subrogate to the creditor but takes a direct share-based recourse from the other guarantors.

\subsection{Analysis of the Specific Recovery Program}

The author advocates that relevant judicial interpretations be enacted to clarify the recourse rights of the guarantor to the hybrid joint security, and refer to the method in the Japanese Civil Code, i.e. the guarantor may directly seek compensation from other guarantors, as this is more in line with the principle of efficiency, and may save judicial resources. Next, we will further analyze the guarantor's internal party of recourse.

In academic circles, the general model is average theory, that is, the total share to be assumed by the guarantor should be equally shared according to the number of guarantors. (Zheng Yubo, 1981) Another theory is proportional theory, that is, the internal liability apportioned among guarantors should be determined according to the proportion of each guarantor's secured debt. (Huang Li, 2003) The share of debt is determined by the proportion of the debt that is secured by the debt itself. Chinese Taiwan has also established the proportional method of recovery. The author believes that the "proportional theory" is relatively fair. The author believes that the internal recourse rights of the guarantor in hybrid joint security in a hybrid joint security can be somewhat analogous to bankruptcy proceedings. The insolvency cases handled through judicial proceedings and the internal recourse rights of the guarantor refers to the debtor's insolvency and the right of a guarantor to request repayment from other guarantors after a certain guarantor fulfills the guaranteed debt. Therefore, the author believes that a certain debt insolvency can be 
referred to the bankruptcy procedure of corporate insolvency of all debts, "external in order, internal in proportion". The "external order" means that the debt will be paid and the liability will be assumed in accordance with the autonomy of the parties, and if there is no agreement between the parties, the debtor will pay the debt, and then the debtor's own security will pay the debt, and finally the joint guarantee, the third party guarantee, and the hybrid guarantee, which are all ranked in the same value order, will pay the debt. "Proportional order" means that in the same value order, each guarantor should be allocated according to the risk proportion agreed in the contract, and the in rem guarantor and the guarantor should bear the debt proportionally, among which the most difficult to determine the debt proportion of the complex situation for the property security and personal security co-exist. Then the specific scheme can be if the value of the collateral is greater than the value of the debt to be assumed, then the value of the debt to be assumed is the limit, if the value of the collateral is less than the value of the debt to be assumed, then the value of the collateral is the limit, the liability of the guarantor is equal to the value of the debt to be assumed, the sum of these three, and then divide the value of the debt to be assumed by each guarantor by that sum to arrive at the proportion of the debt to be assumed by each guarantor.

The above scheme is shown by a case: Apple and Banana have a debt of 20 million, of which Apple's own security is 5 million, A provides 20 million property security, B provides 5 million property security, $\mathrm{C}$ provides personal security, then the specific liability is assumed in the first step, "external in order", Apple's self-bond should be paid off first, at this time there are still remaining. The second step is "proportional in internal", A is limited to the value of the remaining debt is 15 million, $\mathrm{B}$ is limited to the value of the collateral is 5 million, $\mathrm{C}$ is 15 million, the total is $1500+500+15=35$ million, then $\mathrm{A}$ must bear $1500 / 3500$, that is $3 / 7$ of the remaining debt ratio, B has to bear the $1 / 7$ of the remaining debt ratio, and $\mathrm{C}$ has to bear $3 / 7$ of the remaining debt ratio.

However, in today's fast growing economy, all kinds of contracts tend to be continuous and floating, which means that the previous contract is not yet finished and the next contract has already continued, and the guarantee liability of the previous one may be only partially realized, while the latter guarantor has already assumed a new round of guarantee for the remaining liability. Then the liability of the guarantor will be different depending on the point of time chosen. He Jian summarizes the different points of time chosen into two options, which are called "ex-ante liability risk theory" and “ex-post expectation liability theory" (He Jian, 2017).

The author believes that the "ex-post expectation liability theory" is consistent with the doctrine of purpose, because the guarantor should foresee that from the establishment of the security to the realization of the security liability is a dynamic process, and its liability is the liability after the debtor fails to pay the debt when it is due, which should be an ex post facto expectation. If the "ex-ante liability risk theory" is followed, then the debtor's partial satisfaction will not be taken into account or affected by the guarantor, which is obviously unreasonable.

\subsection{Procedural Recommendations for Exercising the Internal Recourse Rights of the Guarantor in Hybrid Joint Security}

As mentioned above, the internal recourse right of the guarantor in a hybrid security should be legally clarified, i.e., after the guarantor assumes responsibility when the debtor is unable to assume the debt, it must first recover from the debtor and only hand over to other guarantors for debt sharing if the debtor cannot compensate. However, there are various situations procedurally: the guarantor who assumes the debt must first sue the debtor, and then sue the other guarantors to assume their liability if the debtor's entire legal estate is enforced and still cannot satisfy its liability, or sue both the debtor and the other guarantors at the first suit, and sue both as a whole, i.e., as co-defendants, or, to sue only the other guarantors but not the debtor, or to sue only one guarantor but not all of them.

In fact, in practice, although the main debtor as the final bearer of the debt, the guarantors are well aware that the debtor has a high probability of insolvency. If the plaintiff is forced to first prosecute the debtor, and then the part of its compensation can not be sued other guarantors, it is obviously not in line with the principle of efficiency of the law, that is, the process is complex and meaningless. Therefore, we can consider that the guarantor who assumes responsibility for the proceedings has a free choice to choose the debtor and the guarantor as co-defendants on its own initiative. That is, to exercise its right to double recovery. But at this time, the debtor as the ultimate bearer, the proportion of its assumption and the proportion of the debt assumed by other guarantors must be different. How to share the proportion of liability between guarantors is a major problem in exercising the right of recovery, and the method of sharing the proportion mentioned above is also feasible here. However, the amount of the guarantor's liability can only be clearly known after the principal debtor takes the initiative to pay off, or its property is enforced. Although, the liability assumed by the guarantor changes with the amount of the debtor's satisfaction, i.e., if the debtor is fully satisfied, there is no sharing ratio between the guarantors, and if not fully satisfied, there is a sharing ratio. However, the percentage of contribution between co-guarantors does not change.

\subsection{Invoking Joint and Several Liability in Civil Liability to Support the Rights to Recovery}

Article 392 of the Civil Code can.... which is also very similar to the expression "joint and several liability", and when the guarantor cannot recover from the debtor after assuming responsibility, the "community of responsibility" needs to reallocate its responsibility as a whole. And then, even if there is no agreement between the guarantors, there must be a certain proportion of sharing. At this time, if the guarantor's liability does not exceed its share, there is no recovery, but if the guarantor's share exceeds its share, there is a right of recourse against the other guarantors for the part that exceeds its share, which is similar to the recourse between joint and several liability holders in civil liability. Article 178 of the Civil Code provides that in the case of joint and several liability, there is a logical proportion of contribution, i.e., any 
guarantor who bears more than his proportion has the right to recover from the other guarantors, and the aforementioned guarantors act as a "community of liability", i.e., the joint and several debtors, as described here. The aforementioned guarantors act as a "community of responsibility", i.e., joint and several debtors. Therefore, the rights of internal recovery of the hybrid guarantee can be regulated by Article 178 of the Civil Code.

However, the last clause of Article 178 of the Civil Code provides that joint and several liability is provided by law or agreed upon by the parties. In reality, if the guarantors have an interesting contact with each other, there is no question of sharing these responsibilities, but in reality the guarantors often do not agree with each other or are not aware of the existence of other guarantors. Article 392 of the Civil Code does not explicitly provide for joint and several liability between guarantors, and there is no provision for the proposed joint and several liability between guarantors without meaningful contact, therefore, in order to fill this gap, this article advocates a corresponding judicial interpretation later, i.e., a judicial interpretation of Article 392 of the Civil Code, i.e., a system of joint and several liability to compensate for the internal recourse rights of guarantors in hybrid joint security.

\section{Conclusion}

The hybrid joint security is an important type of security in the social and economic life; however, there is still no unified formation of the provisions on the internal rights of recourse of the guarantor under in the hybrid joint security after several amendments and judicial interpretations, which makes it difficult for the judges in judicial practice, and results in judgment of similar cases may be completely different.

\section{References}

[1] Cheng Xiao. Guarantor's right of recovery and right of subrogation in mixed joint security-Understanding of Article 176 of the Property Law[J]. Politics \& Law, 2014 (6).

[2] Gao Shengping. Study on mixed joint guaranteeTaking Article 176 of the Property Law as the object of analysis, law science[J]. Journal of Northwest College of Political Science and Law, 2008 (2).

[3] Gu Xiewei. The systematic interpretation of mutual recourse rights of guarantors in the Civil Code $[\mathrm{J}]$. People's Court Newspaper, 2020.

[4] He Jian. Out of the "fair" misunderstanding of the internal recovery of co-guarantors: the interpretation of Article 176 of the Property Law $[\mathrm{J}]$. Jurisprudence, 2017(3).

[5] Huang Li. The treatise on debt of Civil Law[M]. China University of Political Science and Law Press, 2003.

[6] Huang Zhong. The evidence of internal recourse of mixed joint guarantees and its unfolding-The interpretation of Article 176 of the Property Law[J]. Chinese and Foreign Law, 2015(4).

[7] Liu Kaixiang. Denial of internal recourse under mixed joint security[J]. Journal of Lanzhou University, 2021 (3).
[8] Liu Ping. A new understanding of mixed joint guarantee in the compilation of civil code: An additional comment on Article 176 of the Property Law[J]. Journal of Southwest University of Political Science and Law, 2017 (6).

[9] Liu Xihua. Study on internal recourse rights of mixed joint guarantee-Comments on Article 56 of the Minutes[J]. Legal System and Economy, 2020 (04).

[10] Mei Xiaying, Gao Shengping. A tutorial on Property Law[M]. People's University of China Press, 2007.

[11] Qu Tao. Latest Japanese Civil Law[M]. Law Press, 2006.

[12] Wang Liming. The right of recovery under mixed joint security shall be provided for in the part of real right of the Civil Code[J]. Oriental Law, 2019.

[13] Zheng Yubo. The Debt Series of the Civil Law[M]. 1981.

\section{Author Profile}

Xinyu Wu received the B.S. degree in Shanghai Normal University in 2019 and is studying in Master Degree of law in Shanghai Normal University. 